\title{
Concepción del mundo de los docentes y rendimiento académico de los estudiantes
}

\author{
Amawtakunap pachakaap lisiynin \\ yaćhapakukunap yaćhaynin milay
}

\author{
Igenganeegi ogomeantaigatsi aike \\ omonkarata igotaneegi janekijegipage
}

\author{
Recibido: 29 enero 2020 Aprobado: 15 junio 2020 \\ Régulo Pastor Antezana Iparraguirre \\ Nacionalidad: Peruana \\ Filiación: Universidad Nacional de Huancavelica \\ Correo: regulo.antezana@unh.edu.pe \\ ID ORCID: https://orcid.org/oooo-00o3-2822-6186
}

\section{Resumen}

La interpretación y transformación de los fenómenos sociales, naturales y del pensar, se manifiesta solo a través de dos concepciones del mundo: idealista o materialista. No hay una tercera posibilidad. Por ejemplo, el idealismo en torno al problema del proceso histórico, justifica la crisis de la formación capitalista como un problema, fundamentalmente espiritual del hombre, y que la desintegración de dicha sociedad será la desaparición de la "cultura universal". En contraposición a ella, el materialismo dialéctico sostiene, que como materia social que somos, también nos sometemos a las leyes de movimiento social; no existe materia en movimiento arbitrario, sin rumbo u orientación y que estamos sujetos a determinadas leyes sociales. La educación como factor importante en el desarrollo o el fracaso de la sociedad, lleva a los profesores, el mérito o la responsabilidad, respectivamente. Por tanto, ¿qué relación existe entre la concepción del mundo de los profesores con el rendimiento académico de sus estudiantes?
Palabras clave:

Concepción del mundo, rendimiento académico

\section{Lisichiku limaykuna:}

Pachakap lisiynin, yaćhay milayninwan.

Katingatsaro nibarintsipage: Pigotokotagetagani timagantsigite aike irogotaneegi janekijegi.

\section{Datos del autor}

Régulo Pastor Antezana Iparraguirre docente e investigador en Ciencias y Humanidades. Doctor en Ciencias de la Educación por la Universidad Nacional de Huancavelica. 


\section{Conception of the World of Teachers and the Academic Performance of Students}

\begin{abstract}
The interpretation and transformation of social phenomena, natural and of thinking, is manifested only through two conceptions of the world: idealistic or materialistic. There is no third possibility. For example, the idealism around the problem of the historical process, justifies the crisis of capitalist formation as a problem, fundamentally spiritual of man, and that the disintegration of said society will be the disappearance of the "universal culture". In opposition to it, dialectical materialism holds, that as a social matter we are, we also submit ourselves to the laws of social movement; there is no material in arbitrary movement, without direction or orientation and that we are subject to certain social laws. Education as an important factor in the development or failure of society, leads to teachers, merit or responsibility, respectively. Therefore, what is the relationship between the teachers' conception of the world and the academic performance of their students
\end{abstract}

\author{
Keywords \\ Conception of the world, \\ academic performance
}

\section{Concepção do mundo dos docentes e o rendimento acadêmico dos estudantes}

\begin{abstract}
Resumo
A interpretação e transformação dos fenômenos sociais, naturais e do pensar se manifesta apenas através de duas concepções do mundo: idealista ou materialista. Não há terceira possibilidade. Por exemplo, o idealismo em torno do problema do processo histórico justifica a crise da formação capitalista como um problema, fundamentalmente espiritual do homem, e que a desintegração da referida sociedade será o desaparecimento da "cultura universal". Em oposição a ela, o materialismo dialético sustenta, que, como matéria social que somos, também nos submetemos às leis do movimento social; não há matéria no movimento arbitrário, sem direção ou orientação e que estamos sujeitos a certas leis sociais. A educação como fator importante no desenvolvimento ou fracasso da sociedade, leva aos professores, mérito ou responsabilidade, respectivamente. Portanto, qual é a relação entre a concepção do mundo dos professores e o desempenho acadêmico de seus estudantes?
\end{abstract}

\section{Palavras-chave:}

Concepção do mundo, desempenho acadêmico 


\section{Introducción}

La comprensión e interpretación de los fenómenos que ocurren en la naturaleza, sociedad y el pensamiento humano, solo es posible a través de dos concepciones del mundo: idealista o materialista, entre la doctrina burguesa y la comunista, el idealismo y el materialismo, la metafísica y la dialéctica materialista, cada una de ellas, presentadas actualmente en diversas corrientes filosóficas: neopositivismo, existencialismo, neotomismo, materialismo mecánico, revisionismo, anarquismo, materialismo dialéctico e histórico.

En torno al problema del proceso histórico se desprende una permanente lucha ideológica, dado que las distintas formas de interpretarlo se hallan vinculadas a la evaluación del presente y el futuro. El idealismo justificando la crisis de la formación capitalista, presenta ésta como un problema fundamentalmente espiritual del hombre, interpretando que la desintegración del capitalismo será la desaparición de la "cultura universal". Tal es así, que el filósofo religioso E. Brightman, presenta esta contradicción del siguiente modo:

El mundo personal es el mundo de conflicto interno y externo. Los individuos y las sociedades se encuentran en conflicto a muerte entre sí y no saben cómo pararse...El peor de todos es el conflicto interno de cada persona. El alma se encuentra en estado de conflicto a causa de sus deseos, de sus conocimientos, de su ignorancia y sus prejuicios, de su debilidad y su fuerza, de sus ambiciones y sus temores, de su crueldad y su conciencia. (Citada por la Academia de Ciencias de la URSS, 1975, p. 359).

Asimismo, el filósofo Max Scheler, entrando en contradicción entre la ciencia y la concepción del mundo del hombre, afirma: “La ciencia -con mayor motivo cuanto más seria, rigurosa y libremente se la entiende y utiliza en general sin prevenciones- no tiene, en esencia, ninguna importancia para adquirir y afianzar una concepción del mundo." (Citada por Academia de ciencias de la URSS, 1975, p. 360).

La doctrina idealista, defendida por filósofos burgueses, aún no ha sido capaz de proponer soluciones científicas a los problemas más importantes de la vida. Cada vez que el imperialismo, atraviesa por una crisis, evidencia también su profunda crisis ideológica, principalmente en su concepción filosófica del mundo. Entonces, estos filósofos se encuentran imposibilitados de resolver los problemas; como el problema del ser, del conocimiento; es decir incapaces de revelar las fuerzas que determinan el desarrollo social y sus leyes que ponen su movimiento.

Los filósofos burgueses, no han podido descubrir la 'lógica del ser social'. Semejante tarea, les imposibilita, descubrir estas leyes de la historia, por recelo, en que alguien le reemplace contrario a lo que desea, o contrario a sus intereses, o en todo caso por demasiada perturbación angustiosa, por el riesgo de perder su dominación, y por tanto lo conduciría definitivamente a extinguirse, y obviamente será el triunfo de la clase proletaria. (Mao, 1971, pp. 106-107).

Mientras que otro grupo de intelectuales afirman, que como materia social que somos, también nos sometemos a las leyes de movimiento social. Nuestro desarrollo no corresponde a un movimiento arbitrario, sin rumbo u orientación, estamos sujetos a ciertas leyes sociales que el hombre sabiamente puso al descubierto.

La historia reconoce que la clase burguesa cumplió su tarea progresista y revolucionario en la lucha contra la ideología feudal. Sin embargo, en la actualidad se ha convertido en una sociedad caduca, y debe ser ocupado por una nueva y viable; “...pacíficamente, - planteaba Engels 
(1975, p. 15) - si lo viejo es lo bastante razonable para resignarse a morir sin lucha; por la fuerza, si se opone a esta necesidad." Todo lo que existe “...es decir, todo lo que crece de día en día es racional, y todo lo que de día en día se descompone es irracional y, por lo tanto, no ha de evitar la derrota." (Stalin, 1972, p. 18). No obstante, ellos evitan conocer esta y otras leyes sociales.

El mundo se va moviendo con tres grandes contradicciones: la guerra entre países imperialistas, la lucha incesante entre países opresores con los oprimidos, y, entre la burguesía y el proletariado. Para conservar su poder, como clase dominante requiere organizarse externa e internamente.

Por ejemplo, Martínez Rangel \& Reyes Garmendia (2012, p. 36) demuestran que los acuerdos que asumieron los miembros del Consenso de Washington, hace más de veinte años, aproximadamente, “...siguen vigentes y son las más influyentes en las economías de muchos países de América Latina, gracias a que éstas forman parte de las condiciones que los organismos internacionales imponen a sus países miembros principalmente cuando éstos necesitan préstamos." Por tanto, “El neoliberalismo se instauró con éxito en la vida económica de América Latina, a partir de las políticas económicas, primero de Bretton Woods en la posguerra y del Consenso de Washington en la década de 1990." (Martínez Rangel \& Reyes Garmendia, 2012, p. 64).

Casualmente en el Perú y otros países de América Latina, se produjo transformaciones sustanciales a partir de la década del 90 del siglo pasado, fundamentalmente cambios en la Constitución Política de Estado, imprimiéndose la "libre competencia", "el libre comercio" y otros términos referidos al principio burgués: "lo privado es mejor que lo público" En el campo educativo, sus cambios fueron desde la orientación metodológica y conceptual del proceso enseñanza aprendizaje, hasta la eliminación de la asignatura de filosofía, porque conocen que "La filosofía tiene la particularidad de ser una ciencia de efecto universal...no se restringe a esferas locales, nacionales o continentales." (Cerrón, 1989, p. 6o).

Por otro lado, el rendimiento académico de los estudiantes del Perú no es tan atractivo, en comprensión lectora, habilidades matemáticas y ciencia, con respecto a los resultados de países vecinos de América Latina y el mundo. Así lo evidencia los puntajes obtenidos en las pruebas PISA, donde cada tres años, el Perú participa en este proceso, ubicándose en los últimos lugares (OCDE, 2016). Asimismo, a nivel nacional desde el año 2015, se aplica a estudiantes del segundo grado del nivel secundario, la Evaluación Censal a Estudiantes (ECE), cuyo reflejo deja mucho que desear, encontrándose Huancavelica en el nivel previo al inicio en lectura y Matemática (SICRECE, 2016).

El resultado del trabajo, en el plano educativo, permite recomendar a los docentes, tomar la decisión de formarse bajo una determinada concepción del mundo, que verdaderamente contribuya el mejoramiento del rendimiento académico de sus estudiantes. Además, en el ámbito político, hará posible que los responsables del diseño de políticas educativas, no sólo de Huancavelica, sino a nivel nacional, propongan dentro del desempeño docente, estudios y actualizaciones referidos a todo un conjunto de informaciones, explicaciones e interpretaciones, pero con argumentos y fundamentos científicos, en cuanto al arte, filosofía, ciencia, moral, derecho, política, etc., de tal manera, que el docente se encuentre formado e informado del acontecer social, natural y del pensamiento humano; de esta manera los profesores eviten el oportunismo, la individualismo, el egoísmo, entre otras situaciones que dañen su labor de maestro y del estudiante, y como tal a la sociedad en su conjunto. 


\section{Antecedentes de estudio}

La salvadoreña, Lambruschini (1997), en Filosofía Oriental en la Concepción del Hombre, difunde la concepción del mundo del hombre oriental y su relación con el mundo occidental, iniciándose en esta perspectiva una nueva cosmovisión acerca de aspectos tratados por el hombre durante su existencia, cuya filosofía oriental viene imponiéndose en la parte occidental.

En América del Sur, el colombiano Cantero (1997), en sus postulados sobre Incidencia de la Escolástica sobre la Teología en General en el Medioevo, en la Edad Moderna y en la Edad Contemporánea, plantea que la escolástica es una corriente que reaccionó a todo tipo de relación de la teología con la ciencia, esa filosofía es el fundamentalismo. Esta corriente filosófica, reacciona contra la crítica bíblica moderna, la teología liberal y la reformista del evangelio social, que eran los verdaderos motivos de la controversia. Lo que hace que esta concepción refleja una clara tendencia fundamentalista.

Antezana (2010) en su tesis: La concepción filosófica predominante en los docentes de la Región Huancavelica, a finales del pasado milenio y principios del presente, concluye, que con la restructuración del capitalismo y producto del inicio del repliegue político general del proletariado, aproximadamente a partir de 1985; el cual se incrementa desde la última década del siglo pasado, hasta el presente milenio, la mayoría en los docentes de la Región Huancavelica se viene imponiendo una concepción idealista del mundo, con tendencia neopositivista y católica neotomista.

Monrroy (2012) de la Universidad San Ignacio de Loyola de Lima, en su tesis Desempeño docente y rendimiento académico en Matemática de los alumnos de una Institución Educativa de Ventanilla - Callao, y con el objetivo de establecer si existe relación entre el desempeño docente y el rendimiento académico de dichos alumnos en el Área de Matemática, llegó a las siguientes conclusiones: Encontró una correlación positiva entre el rendimiento académico y las prácticas pedagógicas del desempeño docente. Asimismo, existe una correlación positiva entre el rendimiento académico y la responsabilidad en funciones laborales del desempeño docente, aspecto que incide en mayor medida en comparación con las otras dimensiones; $y$, una correlación positiva entre el rendimiento académico y las relaciones interpersonales del desempeño docente.

Gutierrez (2003) citado por Monrroy (2012, p. 6) en su trabajo de investigación, Relación entre el desempeño docente y el rendimiento académico de estudiantes de la EBR de Lima Metropolitana en el año 2003, determina "que el promedio del rendimiento académico del grupo de alumnos que tuvo profesores con desempeño eficiente, es mayor que el promedio del grupo de alumnos que tuvo profesores con desempeño no eficiente."

Barriga (1985) de la Universidad Nacional Mayor de San Marcos, citado por Monrroy (2012, p. 7) en su tesis: Influencia del docente en el rendimiento académico del alumno, concluye que los factores docentes en la determinación del rendimiento académico escolar, dependen del área curricular y el tipo de rendimiento académico, aunque la variable conducción y organización pedagógica presenta incidencias de mayor significatividad; además, los aspectos conductuales y actitudinales de los docentes parecen ser más importantes que los cognoscitivos.

\section{Concepción del mundo}

A lo largo de la historia del conocimiento del hombre, permanentemente han estado presentes dos concepciones, en constante lucha, pugna y controversia, acerca de las leyes del 
movimiento y desarrollo de la materia inorgánica, orgánica y social: una es la concepción dialéctica materialista, y la otra, la concepción idealista del mundo.

Según como se resuelva el problema de la relación entre el ser y el pensar, se distinguían o se dividían en dos grandes grupos. Los que afirmaban, decía Engels (1975, p. 28), "El carácter primario del espíritu frente a la naturaleza, y por tanto admitían, en última instancia, una creación del mundo...formaban en el campo del idealismo. Los otros, los que reputaban la naturaleza como lo primario, figuran en las diversas escuelas del materialismo."

Marx y Engels (1974, p. 22) interpretaba en su libro Ideología Alemana, respecto al hombre intelectual, al hombre teórico con relación a la vida real:

No se parte de lo que los hombres dicen, se representan o se imaginan, ni tampoco del hombre predicado, pensado, representado o imaginado, para llegar, arrancando de aquí, al hombre de carne y hueso; se parte del hombre que realmente actúa y, arrancando de su proceso de vida real, se expone también el desarrollo de los reflejos ideológicos y de los ecos de este proceso de vida.

Por tanto, debe partirse siempre de las condiciones reales, pero no mecánicamente, sino en su movimiento, en su contradicción, en su proceso de desarrollo real, impuesto por las condiciones objetivas que se presenta; es la vida que determina la conciencia de los hombres, y no es la conciencia la que determina la vida Marx (1986).

En ese sentido, la concepción del mundo es un conjunto de ideas, representaciones, imágenes y convicciones, que tiene el ser humano, para explicarse los fenómenos que ocurren en la naturaleza, sociedad y el pensamiento del hombre.

La concepción del mundo visto desde el plano político-social, Mariátegui (1988a, p. 19), sostenía lo siguiente:

Pero, en uno y otro bando hay diversos matices; pero los bandos son neta e inconfundiblemente sólo dos. El bando de los que quieren realizar el socialismo colaborando políticamente con la burguesía; y el bando de los que quieren realizar el socialismo conquistando íntegramente para el proletariado el poder político.

La historia demostró, que en una sociedad dividida en clases, la concepción del mundo, tiene sello de clase, y “...por regla general, la dominante es la concepción del mundo de la clase dominante...” (Rosental, 2005, p. 105).

\section{Formación socioeconómica}

La Academia de Ciencias de la URSS (1975, p. 78), sostiene que la formación socioeconómica “...es un tipo determinado de sociedad, un sistema social íntegro, que funciona y se desenvuelve de acuerdo con sus leyes específicas sobre la base de un modo de producción concreto." Cabe recordar que, dentro de la formación socioeconómica, se encuentra otros fenómenos y relaciones sociales, se orienta desde la base material hasta el modo de pensar del hombre.

Los estados latinoamericanos, con el carácter que tiene su economía, permanecerá si continúa la penetración imperialista. “La condición económica de éstas repúblicas, - soste- 
nía Mariátegui (1996, p. 87) - es, sin duda, semicolonial, y, a medida que crezca su capitalismo y, en consecuencia, la penetración imperialista, tiene que acentuarse este carácter de su economía.", asimismo, "Sobre una economía semifeudal no pueden prosperar ni funcionar instituciones democráticas y liberales." Mariátegui (1996, p. 106). Una sociedad alimentada de semifeudalidad y semicolonialidad, evidencia la presencia del imperialismo, posición que debe sostenerse en alianza con la clase dominante, correspondiente a su país.

Según Marx (1986, p. 7), en su libro Introducción a la Crítica de la Economía Política, planteaba la íntima relación entre los elementos del modo de producción de una sociedad:

En la producción social de su vida, los hombres entran en determinadas relaciones necesarias e independientes de su voluntad, relaciones de producción que corresponden a una determinada fase de desarrollo de sus fuerzas productivas materiales. El conjunto de estas relaciones de producción forma la estructura económica de la sociedad, la base real sobre la que se levanta la superestructura jurídica y política y a la que le corresponden determinadas formas de conciencia social. El modo de producción de la vida material condiciona el proceso de la vida social, política y e intelectual en general. No es la conciencia del hombre del hombre la que determina su ser, sino, por el contrario, es su ser social el que determina su conciencia.

Entonces es la base económica, el ser social la que determina o condiciona a la superestructura o conciencia social, por tanto,

No podemos juzgar a un individuo por lo que él piensa de sí, no podemos juzgar tampoco a estas épocas de conmoción por su conciencia. Por el contrario, hay que explicarse esta conciencia por las contradicciones de la vida material, por el conflicto existente entre las fuerzas productivas sociales y las relaciones de producción. (Marx, 1986, p. 8).

Entonces la solución no está en el pensamiento, sino en las contradicciones internas de las condiciones materiales, en su base material, y ésta refleja en nuestra conciencia, para su respectiva mediata o inmediata acción o reacción.

Asimismo, encontramos en la Carta de Engels dirigida a Josep Bloch Königsberg, lo siguiente:

Según la concepción materialista de la historia, el factor que en última instancia determina la historia es la producción y la producción de la vida real. Ni Marx ni yo hemos afirmado nunca más que esto. Si alguien lo tergiversa diciendo que el factor económico es el único determinante, convertiría aquella tesis en una frase vacua, abstracta, absurda. La situación económica es la base, pero los diversos factores de la superestructura que sobre ella se levanta, ejercen también su influencia sobre el curso de las luchas históricas y determinan, predominantemente en muchos casos, su forma. (Marx \& Engels, 1968, pp. 717-718).

Entonces, existe una interacción e interrelación dialéctica entre la base económica y su correspondiente superestructura, sabiendo que el primero pasa a determinar al segundo, y éste se comporta como influyente al primero; en muchas ocasiones lo segundo (influyente) determina al primero. 


\section{La ideología como formas de conciencia social}

Toda persona recoge información la realidad objetiva, a través de sensaciones, percepciones e imágenes. Algunos en mayor y otros en menor grado de interpretación y análisis de su realidad. Estas formas y fenómenos distintos que se presenta en el hombre, durante el proceso de evolución y desarrollo, de la sociedad y la naturaleza, se manifiestan teóricamente y su práctica, a través del arte, la moral, el derecho, la política, la filosofía, la educación, la religión y la ciencia.

Al respecto, Lora (2006, p. 18) expresaba lo siguiente:

Cada ser humano - en el contexto particular de su pertenencia a una determinada clase social y en el contexto general de la sociedad - posee una mayor o menor (o nula) percepción científica de la realidad objetiva, cada individuo tiene una jerarquización, una gradación, una escala para la compresión, explicación, interpretación y transformación de la naturaleza y de la sociedad.

Cada individuo, interpreta y transforma la realidad, a través del arte, la moral, el derecho, la política, la filosofía, la educación, la religión y la ciencia, los mismos que se hallan sujetos a una determina concepción del mundo. A continuación, presentamos aspectos generales de las formas de conciencia social.

\section{El arte}

El arte es el reflejo de la realidad objetiva, en la materia altamente desarrollada; el cerebro, a través de imágenes artísticas, dentro de una existencia social determinada. Lo que refleja son las vivencias, costumbres, hábitos, etc., de una sociedad o realidad objetiva, bajo una concepción del mundo.

Existe claro está, un arte y una literatura para los explotadores y los opresores. El arte y la literatura para la burguesía son arte y literatura burgueses, además, en el mundo actual, toda cultura, todo arte y literatura pertenecen a una clase determinada y están subordinados a una línea política determinada. (Mao, 1972, p. 74).

Lo que quiere expresar, es la existencia de un arte y literatura al servicio de una clase social determinada, el cual tiene el poder y control económico, político e ideológico, de una nación. Es decir, que el arte no puede estar desligado de la cuestión política, toda vez que el arte y literatura están subordinados a una determina política, planteado por un reducido número de clase social; los burgueses. Pero en la comunidad primitiva fue totalmente distinto y ajeno, dado que, en dicha etapa, el hombre no tenía la capacidad de diferenciar este fenómeno y las otras formas de conciencia social.

Siempre la burguesía quiere del artista un arte que corteje y adule su gusto mediocre. Quiere, en todo caso, un arte consagrado por sus peritos y tasadores. La obra de arte no tiene, en el mercado burgués, un valor intrínseco sino un valor fiduciario. Los artistas más puros no son casi nunca los mejor cotizados. (Mariátegui, 1988b, p. 13). 


\section{La moral}

Según Lora (2006, p. 26), la moral es un conjunto de "reglas, normas, preceptos, principios que regulan el comportamiento de las personas entre sí, en relación a la familia, a las clases sociales, al Estado, etc., a partir de las cuales se determinan si los actos humanos son buenos o malos."

La moral ha sido diferente en cada etapa de la sociedad. En la aurora de la historia de la humanidad, los hábitos y costumbres, de los hombres primitivos formaban precisamente su moral, y su autoridad era frecuentemente más fuerte que sus normas y leyes jurídicas de la sociedad en clases. No existía explotación del hombre por el hombre, conjuntamente recogían frutos, tejían las redes, pescaban, cazaban, labraban la tierra y construían sus viviendas, todo pasaba a ser propiedad de la comunidad.

La disciplina, el horario de trabajo se mantenían entonces, por la fuerza de la costumbre, la tradición, la autoridad o el respeto que infundían los más viejos de la tribu o las mujeres, que en aquel entonces no sólo tenían frecuentemente iguales derechos que los hombres, sino que a veces hasta lo superaban. (Lenin, 1960, p. 438).

Se ha demostrado que, en cada época histórica, hubo una moral imperante y diferente a otra. O sea, decía Shishkin (1966, p. 36) "lo que en una época histórica se estimaba como moral, digno de aprobación, es en otras épocas inmoral, digno de ser censurado".

Una vez que se logre la abolición de la sociedad burguesa y como última forma antagónica del proceso social de producción, expresaba Marx (1986, p. 9), "se cierra, por tanto, la prehistoria de la humanidad." Es decir, toca su fin y comienza la historia verdaderamente humana.

\section{El derecho}

Al respecto, Marx \& Engels (1968, p. 46) expresaban en el Manifiesto del Partido Comunista, sobre la actitud de dichos hombres en una sociedad dividida en clases:

Vuestras ideas son en sí mismas producto de las relaciones de producción y de propiedad burguesas, como vuestro derecho no es más que la voluntad de vuestra clase erigida en ley, voluntad cuyo contenido está determinado por las condiciones materiales de existencia de vuestra clase.

El hombre que convive en una sociedad de clases antagónicas, está limitado en su expresión y en su acción, producto de las leyes y normas jurídicas, decretos que dictan la clase dominante, y, por lo tanto, se hallan sujetas a preservar, a legitimar su dominio y sus intereses. Sin embargo, afirma Lora (2006, p. 27), que todos los derechos ganados por el proletariado "no constituye una dádiva hecha generosamente por las clases expoliadoras, sino que además de ser el resultado de la lucha de clases, fue consecuencia de las necesidades que se operaron en el proceso de producción."

Las reglas o normas de la moral tienen relación con las normas jurídicas del derecho, pero estas normas de la moral se transformaron en normas jurídicas, con el cual hace su aparición el 
derecho. Al respecto, Engels (1970) refiere sobre el tema, en su obra Contribución al Problema de la Vivienda lo siguiente:

Que, en una determinada etapa, muy primitiva, del desarrollo de la sociedad, se hace sentir la necesidad de abarcar con una regla general los actos de la producción, de la distribución y del cambio de los productos, que se repiten cada día; la necesidad de velar porque cada cual se someta a las condiciones generales de la producción y del cambio. Esta regla, costumbre al principio, se convierte pronto en ley. Con la ley, surgen necesariamente organismos encargados de su aplicación: los poderes públicos, el Estado. Luego, con el desarrollo progresivo de la sociedad, la ley se transforma en una legislación más o menos extensa. Una vez la legislación se ha desarrollado y convertido en un conjunto complejo y extenso, se hace sentir la necesidad de una nueva división social del trabajo: se constituye un cuerpo de juristas profesionales y con él, una ciencia jurídica. (pp. 602-603).

En consecuencia, el derecho es producto de una sociedad dividida en clases antagónicas, y existirán mientras haya clases. Cuando las normas del derecho dejen de corresponder con los derechos reales de la clase dominante, harán grandes esfuerzos para romper y librarse de la legalidad creado por estos, y que al mismo tiempo serán sustituidos por otras.

\section{La política}

La política, es el medio más eficaz para cumplir el ideal del hombre, y, se engrandece cuando cumple el papel revolucionario. "La política - escribía Mariátegui (1988c, p. 2) - es hoy la única actividad creadora. Es la realización de un inmenso ideal humano. La política se ennoblece, se dignifica, se eleva cuando es revolucionaria. Y la verdad de nuestra época es la revolución."

Para Lora (2006. p. 33), "La política es el conjunto de actitudes teóricas-prácticas, mediante las cuales las clases sociales expresan sus intereses - particularmente económicos - frente a sí y especialmente frente al Estado". Es decir, en la política hallan su expresión en los intereses esenciales de las clases. Estos intereses, lo materializan, a través de la política. Desde la aparición de clases antagónicas, todas las formas de conciencia social (la moral, el arte, la religión, el derecho, la educación, etc.), decía Shishkin (1966, p. 79) “...ha experimentado la extraordinaria influencia de la política de la clase dominante".

La historia demuestra, que la clase burguesa, halla su política agresiva respecto a los países que buscan su libertad, y persigue a las personas combatientes por la paz y el progreso, haciendo uso de todos medios y de las formas de conciencia social. En el mundo esclavista, la actividad política “...fue patrimonio exclusivo de la clase esclavista de los amos griegos, la que utilizó para consolidar su poder estatal, defensa filosófica asumida, v.gr. por Sócrates, Platón, Aristóteles." (Lora, 2006, p. 24). Sin embargo, los esclavos, tuvieron la necesidad de liberarse de las cadenas del poder esclavista, por medio de luchas y sublevaciones; entre las clases de esclavistas y esclavos.

\section{La filosofía}

Se piensa todavía que la filosofía nació con los filósofos: Platón, Sócrates, Aristóteles, entre otros. Esta errónea posición, es resultada de políticas establecidas por las clases que ostentan el poder, cuyo propósito es tergiversar las cosas y de asegurar su dominio económico. 
El origen de la filosofía se debe exclusivamente a los primeros filósofos materialistas griegos, quienes explicaron que la materia y el universo existentes en el espacio y la tierra, se derivaron de procesos infinitos de transformación. Al respecto, Selsam afirma:

Los filósofos, como Tales de Mileto, Anaxímedes de Mileto, Anaximandro de Mileto, Heráclito de Efeso, Empédocles de Agrigento, Anaxágoras de Clazomene, Jenófanes de Colofon, Leucipo, Demócrito de Abdera, Epicuro de Samos, suponían, que esta materia común de la que habían sido derivadas todas las cosas era una de las cuatro sustancias que los griegos consideraban como fundamentales, tierra, aire, fuego y agua, y que este proceso de derivación de las cosas de una sustancia común habían sucedido naturalmente, esto es sin la dirección o intervención de los dioses, y que había ocurrido con arreglo a algunos principios generales o leyes. (Selsam, 1968, p. 11).

Platón, utilizó la filosofía para justificar los intereses de los aristócratas terratenientes griegos, perpetuándose en el poder por una élite que era la única a quien podía confiársele los asuntos del Estado. O sea, la finalidad de la vida para Platón y filósofos era simplemente el conocer, y los esclavos debían solo dedicarse al trabajo, por carecer de esos conocimientos; y por tanto debían trabajar para la clase opresora. En esencia, "la tendencia de Platón no es hacer que la filosofía contribuya al bienestar social, sino imponer más bien un orden social, de modo que haya filósofos en la cúspide de la pirámide de las clases sociales." (Selsam, 1968, p. 19).

Aristóteles, fue uno de los más grandes filósofos idealistas griegos, que se preocupaba más por el conocer en mundo real que le rodeaba. "Pensador enciclopédico que sistematizó creativamente todo el saber de su época - al igual que Demócrito de Abdera y Epicuro de Samos - negando en primer término el mundo de las ideas de Platón." (Lora, 2006, p. 21). Sin embargo, Aristóteles concibió a la sociedad en base a la esclavitud.

\section{La educación}

La educación es un proceso histórico social, cuya finalidad es la formación integral del hombre. Lora (2006, p. 29) refería que, “La educación es la formación integral de la personalidad humana: moral, artística, intelectual, física, etc., con la finalidad de adaptar a los educandos a una determinada sociedad."

La educación en la sociedad burguesa tiene doble significado, decía Suchodolski (1965, p. 24): La educación como proceso de adaptación a las relaciones existentes, adaptación que asegura a sus hijos de la clase dominante las ventajas y privilegios de su clase, y "adapta" a los hijos de la clase oprimida a las condiciones de explotación de su existencia. Y educación como un arma en la lucha contra la opresión, como instrumento moral e intelectual de la joven generación de la clase oprimida - aunque también de todo joven de otra clase que se coloque al lado de la revolución -

En una sociedad de clases, es la clase dominante y su prole, la que viene gozando de esta formación integral. Lo que significa, que la educación, se convierte en “...un instrumento de fortalecimiento del poder de clases en la sociedad clasista porque propaga una ideología adecuada a éste." (Suchodolski, 1965, p. 23). En esta última, la educación juega un papel importantísimo en el seno de una sociedad clasista. Donde el papel del maestro es decisivo en cuanto al cambio a favor de las grandes mayorías. No en el sentido de teórico puro y reformismo pedagógico, sino con la destrucción de la burguesía. 
Significa que toda crítica pura intelectual y abstracta de la pedagogía burguesa se queda en las fronteras del pensamiento 'ideológico', pese a que parezca muy radical...Para destruir las bases de la educación es imprescindible destruir realmente a la burguesía. Por ello es la 'revolución y no la crítica' el fundamento de la reforma pedagógica. (Suchodolski, 1965, p. 25)

La tarea del maestro, es educarles a los individuos con la finalidad de arrancarles lo viejo que tienen en su conciencia. Al respecto, Mariátegui (1973, p. 62), hablaba sobre los efectos que puedan producir la labor de los maestros en el Perú: "De todas las victorias humanas les toca a los maestros, en gran parte, el mérito. De todas las derrotas humanas les toca, en cambio, en gran parte, la responsabilidad." Es decir, el destino de nuestra sociedad, va depender mucho de la labor del maestro; de facilitar al cambio en favor de la clase oprimida o de retardarla.

\section{La ciencia}

Para llegar a un conocimiento científico, debemos iniciar con la práctica, y mediante todo un proceso de abstracción e investigación, llegamos al conocimiento racional, con la finalidad de regresar a la práctica, he allí donde se comprueba su verdadera objetividad.

Respecto a la práctica social, el cual es de primerísima importancia para el conocimiento, Mao (1971, p. 322) indicaba con un ejemplo:

Si quieres conocer, tienes que participar en la práctica transformadora de la realidad. Si quieres conocer el sabor de una pera, tienes tú mismo que transformarla comiéndola. Si quieres conocer la estructura y las propiedades del átomo, que tienes que hacer experimentos físicos y químicos, cambiar el estado de átomo. Si quieres conocer la teoría y los métodos de la revolución, tienes que participar en la revolución. Todo conocimiento nace de la experiencia directa...y de la experiencia indirecta.

Sabemos, que la práctica no puede desarrollarse mucho sin una teoría. Sin embargo, trajo como consecuencia nuevos problemas entre la teoría y la práctica. Históricamente, como en caso de los griegos, la teoría y la práctica se fueron distanciándose más y más, producto de la diferencia de un Estado social. Hasta que la teoría y la práctica, terminaron por separarse.

Lora (2006, p. 28) define a la ciencia, como “un conjunto de hipótesis, leyes, teorías, modelos, etc. que explican causalmente las propiedades de los procesos naturales (naturaleza y sociedad". Pero su veracidad se comprueba en la práctica social, con la finalidad de prever y transformar la realidad en beneficio del hombre.

Muchos autores plantean que las cuestiones morales no tienen nada que ver con la ciencia. Por ejemplo, Shishkin (1966, p. 97) afirma que:

Bertrand Rusell escribía que la diferencia entre un valor moral y otro no es, ni puede ser, objeto de definición científica. Esta diferencia es cuestión de gustos y no una verdad objetiva cualquiera. La ciencia no puede resolver las cuestiones relacionadas a los valores, ya que estos últimos se encuentran fuera del sector de la verdad y del error. Dicho de otro modo, la moral afecta al campo de las emociones, y no al de la razón, y no está en modo alguno relacionada a la verdad. 
Los positivistas, R. Carnap, Ayer, Wittgenstein, entre otros, se oponen a la existencia de una relación entre la moral y la ciencia. Plantean que la moral afecta a la psicología empírica (expresión de emociones), y que las tentativas de hallar sus fundamentos racionales de la moral son estériles.

\section{La religión.}

“Es un producto elaborado por la imaginación humana, como consecuencia de las limitaciones que tuvieron los seres humanos para explicarse científicamente los procesos naturales y sociales." (Lora, 2006, p. 40)

La religión nace como resultado de un determinado conjunto de relaciones de producción, que corresponde a una etapa a la comunidad primitiva. Dentro de esta etapa, el hombre dependía de las fuerzas y fenómenos de la naturaleza, había una impotencia de la lucha con estos, debido al bajo nivel de desarrollo de las fuerzas productivas.

El dominio de la fuerzas y fenómenos de la naturaleza sobre el hombre, la impotencia de éste ante ellos son uno de los factores que dan lugar a la religión. Fue precisamente la debilidad del hombre en su lucha con la naturaleza la que motivó por vez primera en la historia de la sociedad la aparición de la ideología religiosa. (Sujov, 1968, p. 17).

Engels (1968, p. 313) percibe a la religión como “...reflejo fantástico, en las cabezas de los hombres, de los poderes externos que dominan su existencia cotidiana: un reflejo en el cual las fuerzas terrenas cobran forma de supraterrenas."

A lo largo de la historia del conocimiento humano y hasta la actualidad, existen dos concepciones del mundo, que explican sobre los fenómenos que se desarrollan en la naturaleza, sociedad y el mismo pensar: la concepción dialéctica y la concepción metafísica, los cuales son diametralmente opuestas.

\section{Concepción dialéctica materialista}

La concepción dialéctica considera a las cosas en movimiento, cambio, transformación, en un ininterrumpido movimiento infinito, dentro del campo social, natural y el pensamiento humano. Teniendo en cuenta que movimiento, argumentaba Engels (1968, p. 47): "es el modo de existencia de la materia. Jamás y en ningún lugar ha habido materia sin movimiento, ni puede haber haberla. El movimiento no puede, pues, crearse, sino sólo transformarse y transportarse."

Al respecto, Rosental (2005, p. 155) define a la dialéctica como una "ciencia que trata de las leyes más generales del desarrollo de la naturaleza, de la sociedad y del pensamiento humano." Mediante la dialéctica, podemos poner atención constante a la interacción general del devenir y del perecer, de esta manera se logra obtener el movimiento en el universo, a través de las cuales, se hallan gobernado por leyes científicas.

La naturaleza, demostraba Engels (1968, p. 9):

Es la piedra de toque de la dialéctica, y tenemos que reconocer que la ciencia moderna ha suministrado para esa prueba un material sumamente rico y en constante acumulación, mostrando así que, en última instancia, la naturaleza procede dialéctica y no metafísicamente. 
Llevando a la parte social, la dialéctica, según Stalin (1972, p. 18), "todo lo que realmente existe, es decir, todo lo que crece de día en día es racional, y todo lo que de día en día se descompone es irracional y, por tanto, no ha de evitar la derrota." En la vida siempre existe lo nuevo y lo viejo, lo que crece y lo que se extingue o muere, lo revolucionario y lo contrarrevolucionario.

Según Mao (1971, p. 54), con los aportes de Hegel se logra contribuciones importantísimas a la dialéctica, pero su orientación era idealista; y gracias a Marx y Engels, "crearon la gran teoría del materialismo dialéctico e histórico sintetizando todo lo positivo conquistado en la historia del conocimiento humano y, en particular, asimilando críticamente los elementos racionales de la dialéctica hegeliana." Esta teoría ha tenido sus seguidores como: Vladimir Ilich (Lenin), José Stalin, Mao She Tung, entre otros.

Rosental (2005, p. 388) define al materialismo dialéctico, como una "concepción filosófica del mundo, una de las partes componentes del marxismo, su base filosófica." Lo que significa, que el materialismo dialéctico es una ciencia que estudia las leyes más generales del universo.

Sobre cómo estudiar y aplicar la concepción dialéctica materialista y sus respectivas relaciones con otras cosas, Mao (1971, p. 49) plantea lo siguiente:

Debemos considerar que el desarrollo de las cosas es un automovimiento, interno y necesario, y que, en su movimiento, cada cosa se encuentra en interconexión e interacción con las cosas que le rodean. Asimismo, que la causa fundamental del desarrollo de las cosas no es externa sino interna; reside en su carácter contradictorio interno. Esta contradicción es la causa fundamental de su desarrollo, en tanto que su interconexión e interacción con otras cosas son secundarias.

En consecuencia, la dialéctica materialista considera que los cambios de la naturaleza y sociedad son ocasionados principalmente por el desarrollo de sus contradicciones internas, sin embargo, la dialéctica materialista no descarta los factores externos en el desarrollo de las cosas, sino que éstas cosas "constituyen la condición de cambio, y las causas internas, su base que aquéllas actúan a través de éstas.” (Mao, 1971, p. 52).

\section{Concepción idealista}

La concepción metafísica plantea que las cosas se hallan estáticas, sin movimiento, sin contradicción, ni transformación. Es decir, decía Lora (2006, p. 156), “la metafísica en cuanto a método significa generalmente que no hay cambio, no existe movimiento, contradicción, transformación, progreso, desarrollo; en esencia, no existe unidad y lucha de contrarios en los proceso, fenómenos, objetos, en la realidad."

Según Rosental (2005, p. 301), el idealismo "parte de que lo primario es lo espiritual, lo inmaterial, y lo secundario, lo material." Lo que indica, que el idealismo argumenta o defiende como primaria, la conciencia al margen de la naturaleza, y que se halla vinculada a un creador, a un ser supremo, llamado Dios.

Entonces, para el metafísico las cosas y sus conceptos se encuentran por siempre y para siempre. Por eso, Engels (1968, p. 7) planteaba: 
"Que, para el metafísico, las cosas y sus imágenes mentales, los conceptos, son objetos de investigación dados de una vez para siempre, aislados, uno tras otro y sin necesidad de contemplar el otro, firmes, fijos y rígidos. El metafísico piensa según rudas contraposiciones sin mediación: su lenguaje es "si, si”, y “no, no”, que todo lo que pasa de eso del mal espíritu procede. Para él, toda cosa existe o no existe: una cosa no puede ser al mismo tiempo ella misma y algo diverso. Lo positivo y lo negativo se excluyen lo uno a lo otro de un modo absoluto; la causa y efecto se encuentran del mismo modo en rígida contraposición."

Este modo de pensar traza una barrera, más allá del cual se hace, limitado, tenue, aislado, abstracto y llega a un mundo de contradicciones que no pueden resolver, el devenir y su perecer, porque se aislaron y negaron el movimiento de las cosas y los conceptos e imágenes mentales.

\section{Rendimiento académico}

El rendimiento desde un punto físico, Huerta (2009, p. 197), lo concibe "como un problema que sólo se resolverá de forma científica, cuando se determina la relación existente entre el trabajo realizado por los docentes en interacción con los alumnos, por un lado, y la educación por el otro."

Al referirse a la educación, Huerta lo presenta como un problema relacionado con el perfeccionamiento intelectual y moral lograda por el educando.

Sin embargo, Rodriguez Espinar (1982), citado por Adell (2004, p. 27), añade que "las notas cumplen, además de una finalidad informativa a padres y autoridades académicos, la función de pronóstico puesto que ayudan a saber no sólo dónde está el alumno en cada momento, sino cuáles son sus posibilidades en el futuro."

Asimismo, Adell (2004, p. 27) afirma, aludiendo a Pérez Serrano (1981), que "las notas es un indicador fundamental del rendimiento académico y debemos tener en cuenta las calificaciones a lo largo del curso. Que las calificaciones son el mejor criterio con que se cuenta para definir el rendimiento."

Álvaro Page (1990) comparte la idea con Pérez Serrano, al señalar, “...que cuando, a pesar de reconocer el grado de subjetividad atribuible a las notas, las considera como la medida más utilizable por el profesorado y los centros a la hora de valorar el rendimiento de sus alumnos." (Citado por Adell, 2004, p. 27).

No obstante, las notas no es suficiente indicador para determinar el si se ha logrado o no el rendimiento académico de los estudiantes, sino existe muchos factores que pueden influir o determinar. "Puede ser que a la hora de poner las notas no se consideren suficientemente los procedimientos utilizados, la capacidad de expresarse, para razonar, para aplicar lo aprendido a nuevas situaciones,...e interacciones de con la inteligencia, motivación, personalidad, actitudes, contexto, etc." (Citado por Adell, 2004, p. 27).

\section{Organización de la Educación Básica Regular}

El Ministerio de Educación (MINEDU) organiza la Educación en Básica Regular, Básica Especial y Básica Alternativa. La primera es la modalidad que abarca los niveles de educación 
Inicial, Primaria y Secundaria; los cuales están dirigidas a los niños y adolescentes que pasan oportunamente por el proceso educativo (MINEDU, 2008).

Lineamientos de evaluación de los aprendizajes

Según el MINEDU (2008), la evaluación de los aprendizajes es un proceso pedagógico continuo, sistemático, participativo y flexible, que forma parte del proceso enseñanza-aprendizaje, que se enfocan en dos funciones: pedagógica y social; cuyas finalidades se direccionan a la información continua que le permite al docente, tomar decisiones. Los resultados que presenta en la tabla 1, se encuentran bajo una escala de calificación de los aprendizajes en la Educación Básica Regular, que a continuación se detalla:

Tabla 1.

Escala de calificación de los aprendizajes en la Educación Básica Regular

\begin{tabular}{|c|c|c|}
\hline $\begin{array}{l}\text { NIVEL EDUCATIVO } \\
\text { TIPO DE } \\
\text { CALIFICACIÓN }\end{array}$ & $\begin{array}{l}\text { ESCALAS DE } \\
\text { CALIFICACIÓN }\end{array}$ & DESCRIPCIÓN \\
\hline \multirow{4}{*}{$\begin{array}{l}\text { Educación } \\
\text { Secundaria. } \\
\text { Numérica y } \\
\text { descriptiva }\end{array}$} & $20-18$ & $\begin{array}{l}\text { Cuando el estudiante evidencia el logro de los } \\
\text { aprendizajes previstos, demostrando incluso un } \\
\text { manejo solvente y muy satisfactorio en todas las tareas } \\
\text { propuestas }\end{array}$ \\
\hline & $17-14$ & $\begin{array}{l}\text { Cuando el estudiante evidencia el logro de los } \\
\text { aprendizajes previstos en el tiempo programado. }\end{array}$ \\
\hline & $13-11$ & $\begin{array}{l}\text { Cuando el estudiante está en camino de lograr } \\
\text { los aprendizajes previstos, para lo cual requiere } \\
\text { acompañamiento durante un tiempo razonable para } \\
\text { lograrlo. }\end{array}$ \\
\hline & $10-\infty 0$ & $\begin{array}{l}\text { Cuando el estudiante está empezando a desarrollar } \\
\text { los aprendizajes previstos o evidencia dificultades } \\
\text { para el desarrollo de estos y necesita mayor tiempo de } \\
\text { acompañamiento e intervención del docente de acuerdo } \\
\text { con su ritmo y estilo de aprendizaje. }\end{array}$ \\
\hline
\end{tabular}

Fuente: (MINEDU, 2008)

\section{Metodología}

El método que se utilizó fue el científico, porque se tuvo en cuenta la observación, identificación, selección y formulación del problema, revisión bibliográfica, formulación y comprobación de la hipótesis, y su correspondiente generalización o conclusiones del trabajo de investigación. Cuyo método específico, el descriptivo, porque fue útil, en el sentido de describir las diversas características de la concepción del mundo de los docentes y rendimiento académico de los estudiantes.

Para el recojo de información, se recurrió a la técnica de encuesta cuyo instrumento fue el cuestionario, para recolectar información de la concepción del mundo de 158 docentes; y el rendimiento académico de los estudiantes se obtuvo mediante las actas de evaluación.

\section{Resultados}

Para determinar la correlación de las variables de estudio, se aplicó como parte de técnica de procesamiento estadístico, el Coeficiente de Rho de Sperman, porque las variables, con- 
cepción del mundo y rendimiento académico, pertenecen probabilísticamente a eventos categóricos, cuyos resultados se obtuvieron considerando los datos sin distribución normal. Por considerarse las variables de estudio de tipo categórico, y por ser el cuestionario de tipo dicotómico, nos obliga analizar los datos obtenidos mediante la prueba estadística no paramétrica Chi cuadrado independiente, dado que el trabajo corresponde al nivel investigativo relacional, cuyo objetivo estadístico es la asociación, como continuación del objetivo comparativo.

Por tanto, primero asumimos un análisis comparativo, y finalmente comprobamos, si existe o no asociación entre las variables de investigación, mediada con el valor de probabilidad de la prueba no paramétrica Chi cuadrado, teniendo en cuenta que el p-valor (valor de probabilidad), indica el bajo o alto error que cometemos al afirmar algo, y la aplicación del coeficiente de contingencia para determinar el nivel de asociación.

Tabla 2.

Concepción del mundo de los docentes de las instituciones educativas públicas de la localidad de Huancavelica

\begin{tabular}{lcccccc}
\hline \multirow{2}{*}{\multicolumn{1}{c}{ Institución Educativa }} & \multicolumn{2}{c}{$\begin{array}{c}\text { Concepción del } \\
\text { mundo materialista }\end{array}$} & \multicolumn{2}{c}{$\begin{array}{c}\text { Concepción del } \\
\text { mundo idealista }\end{array}$} & \multicolumn{2}{c}{ Total } \\
\cline { 2 - 8 } & $\mathrm{Fi}$ & $\%$ & $\mathrm{Fi}$ & $\%$ & $\mathrm{fi}$ & $\%$ \\
\hline La Victoria de Ayacucho & 26 & 57.78 & 19 & 42.22 & 45 & 28.48 \\
Francisca Diez Canseco de Castilla & 27 & 62.79 & 16 & 37.21 & 43 & 27.22 \\
Ramón Castilla Marquesado & 14 & 56.00 & 11 & 44.00 & 25 & 15.82 \\
Micaela Bastidas Puyucahua & 11 & 57.89 & 8 & 42.11 & 19 & 12.03 \\
Isolina Clotet de Fernandini & 7 & 70 & 3 & 30.00 & 10 & 6.33 \\
América & 6 & 60 & 4 & 40.00 & 10 & 6.33 \\
San Cristóbal & 5 & 83.33 & 1 & 16.67 & 6 & 3.80 \\
\hline Total & 96 & 60.76 & 62 & 39.24 & 158 & 100 \\
\hline
\end{tabular}

Fuente: Elaboración propia

En la tabla 2 indica, que de 158 profesores (muestra), el 60,76\% tienen la concepción materialista y el $39,24 \%$ son metafísicos. Por tanto, existe más de la mitad de profesores premunidos con la concepción materialista.

Tabla 3.

Concepción del mundo de los docentes por áreas curriculares de las instituciones educativas públicas de la localidad de Huancavelica

\begin{tabular}{|c|c|c|c|c|c|c|}
\hline \multirow[t]{2}{*}{ ÁREAS } & \multicolumn{2}{|c|}{$\begin{array}{c}\text { Concepción del mundo } \\
\text { materialista }\end{array}$} & \multicolumn{2}{|c|}{$\begin{array}{l}\text { Concepción del } \\
\text { mundo idealista }\end{array}$} & \multicolumn{2}{|c|}{ Total } \\
\hline & $\mathrm{Fi}$ & $\%$ & fi & $\%$ & fi & $\%$ \\
\hline Comunicación & 16 & 47.06 & 18 & 52.94 & 34 & 21.5 \\
\hline Matemática & 15 & 44.1 & 19 & $55 \cdot 9$ & 34 & 21.5 \\
\hline Ciencia, Tecnología y Ambiente & 25 & $73 \cdot 5$ & 9 & 26.5 & 34 & 21.5 \\
\hline Formación Ciudadana y Cívica & 18 & $94 \cdot 7$ & 1 & $5 \cdot 3$ & 19 & 12.0 \\
\hline Historia, Geografía y Economía & 10 & 47.6 & 11 & 52.4 & 21 & 13.3 \\
\hline Persona, Familia y Relaciones Humanas & 12 & $75 \cdot 0$ & 4 & 25.0 & 16 & 10.1 \\
\hline Total & 96 & 60.76 & 62 & 39.24 & 158 & 100.0 \\
\hline
\end{tabular}

Fuente: Elaboración propia 
En la tabla 3 informa que, de 158 profesores el 60,76\% tienen la concepción del mundo materialista y $39,24 \%$ la concepción metafísica.

Respecto al rendimiento académico, de 158 estudiantes de las instituciones educativas públicas de la localidad de Huancavelica, el 75,3\%, se encuentra en proceso, 20,9\% en logro previsto, el 3,8\% en inicio, y ninguno en logro destacado. Es decir, que mayoría de ellos se encuentran con rendimiento académico en proceso.

Por tanto, que existe una correlación directa cuyo coeficiente es bueno entre la concepción del mundo de docentes con el rendimiento académico de los estudiantes de educación secundaria de las instituciones educativas públicas de la localidad de Huancavelica, dado que Rho de Sperman obtuvo el valor de o,719.

\section{Contraste de hipótesis de investigación}

$\mathrm{H}_{\mathrm{o}}$ : No existe asociación significativa entre la concepción del mundo de los docentes y el rendimiento académico de los estudiantes de educación secundaria de las instituciones educativas públicas de la localidad de Huancavelica.

$\mathrm{H}_{\mathrm{a}}$ : Existe asociación significativa entre la concepción del mundo de los docentes y el rendimiento académico de los estudiantes de educación secundaria de las instituciones educativas públicas de la localidad de Huancavelica.

\section{Nivel de significancia}

El nivel de significancia es el valor de probabilidad al 5\%; es decir; el p-valor < 0,05. Si el valor de probabilidad ( $\mathrm{p}$-valor) mayor a o,05 se acepta la hipótesis nula y se rechaza la hipótesis alterna. Pero si el valor de probabilidad ( $p$-valor) es menor o igual a o,05 se acepta la hipótesis alterna y se rechaza la hipótesis nula

\section{Decisión teórica}

Según Levin (1979), la prueba de hipótesis para este tipo de investigación se utilizará la Chi Cuadrada independiente $u$ homogénea no paramétrica, por las siguientes razones: Se halla libre de distribución normal, es decir no tienen distribución normal; la variable es categórica, en nuestro caso la concepción del mundo es nominal, y además dicotómica, lo que nos lleva a determinar la medida de asociación con el rendimiento académico; y las muestras obtenidas son aleatorias. (Citado por Yarlequé et al, 2007).

\section{Decisión estadística}

El resultado comparativo entre la concepción del mundo de los docentes con el rendimiento académico de los estudiantes de las instituciones educativas públicas de la localidad de Huancavelica, es como sigue: de 96 docentes con la concepción del mundo materialista, ninguno de sus estudiantes se halla con un rendimiento académico en la escala de inicio, pero $40,5 \%$ de ellos están en proceso y 20,3\% en la escala de logro previsto. Sin embargo, de 62 
profesores con la concepción idealista, 3,8\% de sus estudiantes se hallan en inicio, $34,8 \%$ en proceso y $0,6 \%$ en logro previsto.

Tabla 4.

\section{Resultado de la prueba de Chi Cuadrado de la concepción de los docentes y el rendimiento académico en sus tres escalas}

Pruebas de chi-cuadrado

\begin{tabular}{lccl} 
& Valor & Gl & p-valor \\
\hline Chi-cuadrado de Pearson & $29.869^{\mathrm{a}}$ & 2 & $3.266845294 \mathrm{E}-7$ \\
Razón de verosimilitudes & 38.410 & 2 & .000 \\
Asociación lineal por lineal & 29.477 & 1 & .000 \\
N de casos válidos & 158 & & \\
\hline
\end{tabular}

Fuente: Elaboración propia

En la tabla 4 señala que, siendo $3.266 \mathrm{E}-7$ el valor de probabilidad, el rendimiento académico en sus escalas de inicio, proceso y logro previsto obtenidos, es distinto entre los otros dos con respecto a uno de ellos o, que los tres grupos son diferentes. Por tanto, existe estadísticamente diferencias significativas entre la concepción del mundo de los docentes con el rendimiento académico de los estudiantes en sus tres escalas de calificación, toda vez que $p<$ 0,05 (es decir, $0.0000003266<0.05$ )

No obstante, si comparamos los tres grupos (estudiantes que se encuentran en inicio, proceso y logro previsto) al mismo tiempo, el $p$-valor $=0.0000003266$ significativo no indica que existe diferencias en al menos uno o dos, de estos tres. Para determinar esta diferencia, agruparemos en dos categorías (inicio más proceso, inicio más logro previsto, y proceso más logro previsto), generando tablas de $2 \times 2$, con su respectiva prueba de hipótesis Chi cuadrado y el coeficiente de contingencia. Sin embargo, asumimos el valor de probabilidad igual 0.00000167225 , el cual corresponde a la agrupación entre la escala de calificación de inicio y proceso, cuyos docentes, preferentemente, muestran una concepción materialista del mundo, y al mismo tiempo éste valor es menor, con respecto a los otros dos.

Tabla 5.

Resultado de la concepción del mundo de los docentes con el rendimiento académico de los estudiantes, agrupando la escala logro previsto con inicio y proceso de las instituciones educativas públicas de Huancavelica

\begin{tabular}{|c|c|c|c|c|c|}
\hline & & & \multicolumn{2}{|c|}{ Rendimiento académico del estudiante } & \multirow{2}{*}{ Total } \\
\hline & & & logro previsto & inicio + proceso & \\
\hline \multirow{4}{*}{$\begin{array}{l}\text { Concepción } \\
\text { del mundo de } \\
\text { los docentes }\end{array}$} & \multirow{2}{*}{ Idealista } & Recuento & 1 & 61 & 62 \\
\hline & & $\%$ del total & $.6 \%$ & $38.6 \%$ & $39.2 \%$ \\
\hline & \multirow{2}{*}{ Materialista } & Recuento & 32 & 64 & 96 \\
\hline & & $\%$ del total & $20.3 \%$ & $40.5 \%$ & $60.8 \%$ \\
\hline \multirow[t]{2}{*}{ Total } & & Recuento & 33 & 125 & 158 \\
\hline & & $\%$ del total & $20.9 \%$ & $79.1 \%$ & $100.0 \%$ \\
\hline
\end{tabular}

Fuente: Elaboración propia 
En la tabla 5 se informa, que de todos docentes que ostentan ideas materialistas, 64 $(40,5 \%)$ estudiantes se encuentran en la escala asociada inicio más proceso, y $32(20,3 \%)$ en la escala logro previsto. Sin embargo, aquellos docentes que muestran ser idealistas, $61(38,6 \%)$ estudiantes se ubican en la escala asociada de inicio más proceso. Por tanto, el rendimiento académico de los estudiantes, cuyos docentes ostentan ideas idealistas o materialistas, se hallan en su mayoría en la escala de calificación entre inicio y proceso.

Tabla 6.

Resultado de la prueba de Chi cuadrado entre la concepción de los docentes con el rendimiento académico de los estudiantes, agrupando la escala de logro previsto con inicio y proceso de las instituciones educativas públicas de Huancavelica

\begin{tabular}{lccc}
\hline & Valor & Gl & Sig. asintótica (bilateral) \\
\hline Chi-cuadrado de Pearson & $22.939^{\mathrm{a}}$ & 1 & $1.6722571784122397 \mathrm{E}-6$ \\
Corrección por continuidad & 21.059 & 1 & .000 \\
Razón de verosimilitudes & 29.483 & 1 & .000 \\
Asociación lineal por lineal & 22.794 & 1 & .000 \\
\hline N de casos válidos & 158 & & \\
\hline
\end{tabular}

Fuente: Elaboración propia

Se indica en la tabla 6 que, el valor de probabilidad es igual a 1.67225E-6. Lo que significa, que el $p$-valor es bastante pequeño, igual a 0.00000167 y es menor a 0,05. Además, el valor de coeficiente de contingencia es 0,356 ; indicando que la asociación es positiva buena. En consecuencia, existe asociación significativa positiva buena entre la concepción del mundo del docente y el rendimiento académico de los estudiantes.

Luego, si el p-valor $=0.00000167225$ es menor 0,05; entonces existe asociación significativa positiva buena entre la concepción del mundo del docente y el rendimiento académico de los estudiantes. Por tanto, aceptamos la hipótesis alterna: que existe asociación significativa entre la concepción del mundo de los docentes y el rendimiento académico de los estudiantes de educación secundaria de las instituciones educativas públicas de la localidad de Huancavelica.

\section{Discusión de resultados}

Los resultados obtenidos a partir de los datos recolectados, llegamos a determinar la existencia de una asociación significativa positiva entre la concepción de los docentes con el rendimiento académico de los estudiantes. Este resultado guarda cierta compatibilidad con el trabajo de investigación de la salvadoreña, Lambruschini (1997), en "Filosofía Oriental en la Concepción del Hombre", quien difunde la concepción del mundo del hombre oriental y su relación con el mundo occidental, iniciándose en esta perspectiva una nueva cosmovisión acerca de aspectos tratados por el hombre durante su existencia.

De la misma manera, los resultados concuerdan con la tesis del colombiano Cantero (1997), en sus postulados sobre "Incidencia de la Escolástica sobre la Teología en General en el Medioevo, en la Edad Moderna y en la Edad Contemporánea", quien plantea que la escolástica es una 
corriente que reaccionó a todo tipo de relación de la teología con la ciencia, esa filosofía es el fundamentalismo.

La variable, concepción del mundo de los docentes es relativamente opuesta a los resultados de la tesis, planteada por Antezana (2010), titulada: "La concepción filosófica predominante en los docentes de la Región Huancavelica, a finales del pasado milenio y principios del presente", quien llega a la conclusión que con la restructuración del capitalismo y producto del inicio del repliegue político general del proletariado, aproximadamente a partir de 1985; el cual se incrementa desde la última década del siglo pasado, hasta el presente milenio, la mayoría en los docentes de la Región Huancavelica se viene imponiendo una concepción idealista del mundo, con tendencia neopositivista y católica neotomista.

De forma similar, respecto a los resultados del rendimiento académico, son análogos con algunas conclusiones de Gutierrez (2003) y Monrroy (2012), en su tesis "Desempeño docente y rendimiento académico en Matemática de los alumnos de una Institución Educativa de Ventanilla - Callao". Ambos autores concluyen que el desempeño docente evidencia un factor importante en el rendimiento de los estudiantes, donde existe una correlación positiva entre el desempeño docente (prácticas pedagógicas, responsabilidad en funciones laborales y las relaciones interpersonales).

De la misma manera Barriga (1985) de la Universidad Nacional Mayor de San Marcos, citado por Monrroy (2012, p. 7) en su tesis "Influencia del docente en el rendimiento académico del alumno", son similares con los resultados de nuestro trabajo de investigación. Él plantea que los factores docentes en la determinación del rendimiento académico escolar, dependen del área curricular y el tipo de rendimiento académico, aunque la variable conducción y organización pedagógica presenta incidencias de mayor significatividad; además, los aspectos conductuales y actitudinales de los docentes parecen ser más importantes que los cognoscitivos.

\section{Conclusiones}

La mayoría de los docentes en las áreas curriculares de Formación Ciudadana y Cívica, luego Ciencia, Tecnología y Ambiente, y Persona, Familia y Relaciones Humanas, mantienen una concepción materialista del mundo. Mientras que el resto, correspondientes a las áreas Matemática, Historia, Geografía y Economía, y Comunicación, muestran una concepción del mundo idealista de las instituciones educativas públicas de la localidad de Huancavelica.

Los estudiantes se encuentran con un rendimiento académico, en su mayoría en la escala de calificación de proceso, seguido con el logro previsto, y una mínima proporción, en la escala de inicio.

Existe una correlación positiva buena, entre la concepción del mundo de los docentes y el rendimiento académico de los estudiantes de dichas instituciones; y diferencias estadísticamente significativas entre dichas variables, en las escalas de calificación (inicio, proceso y logro previsto).

Por tanto, se determinó la existencia de asociación significativa positiva buena entre la concepción del mundo de los docentes y el rendimiento académico de los estudiantes, preferentemente entre la escala de calificación inicio y proceso, con respecto a la escala logro previsto. 


\section{Referencias bibliográficas}

Academia Ciencias de la URSS. (1975). Fundamentos de filosofía marxista - leninista (Vol. II). Moscú: Progreso.

Adell, M. (2004). Estrategias para mejorar el rendimiento académico de los adolescentes. Madrid: Pirámide.

Antezana, R. (2010). La concepción filosófica predominante en los docentes de la región Huancavelica, a finales del pasado milenio y principios del presente (Tesis de Maestría). Universidad Nacional de Huancavelica, Huancavelica.

Cantero, M. (1997). Incidencia de la Escolástica sobre la Teología en General en el Medioevo, en la Edad Moderna y en la Edad Contemporánea (Tesis de Maestría). Colombia.

Cerrón, J. (1989). Historia de las ideas del Perú contemporáneo. Huancayo.

MINEDU (2008). Diseño Curricular Nacional de Educación Básica Regular (Segunda Edición). Lima.

Engels, F. (1970). Obras escogidas: Contribución al problema de la vivienda (Vol. I). Moscú: Progreso.

Engels, F. (1968). Anti-Dühring. La subversión de la ciencia por el señor Eugen Dühring. México: Grijalbo, S. A.

Engels, F. (1975). Ludwing Feuerbach y el fin de la filosofía clásica alemana. Lima: Fondo de Cultura Popular.

Huerta, M. (2009). Aprendizaje estratégico. Lima: San Marcos.

Lambruschini, D. (1997). Filosofía Oriental en la Concepción del Hombre (Tesis Doctoral). San Salvador.

Lenin, V. (1960). Obras escogidas. México: Librerías Allende S. A.

Lora, F. W. (2006). Filosofía. Lima: Gutemberg.

Mao. (1972). Obras escogidas (Vol. II). Lima: Lenguas Extranjeras.

Mao, T. (1971). Cinco tesis filosóficas. Lima: Lenguas Extranjeras.

Mariátegui, J. C. (1988a). Historia de la crisis mundial (doce). Lima: Amauta.

Mariátegui, J. C. (1988b). El artista y la época (trece). Lima: Amauta.

Mariátegui, J. C. (1988c). Ideología política (diecisiete). Lima: Amauta.

Mariátegui, J. C. (1973). Temas de educación. Lima: Amauta.

Mariátegui, J. C. (1996). 7 ensayos de interpretación de la realidad peruana (sesenta y tres). Lima: Amauta.

Martínez Rangel, R., y Reyes Garmendia, E. (2012). El Consenso de Washington: la instauración de las políticas neoliberales en América Latina. Política y cultura, (37), 35-64.

Marx, C. (1986). Introducción a la crítica de la economía política. Buenos Aires: Anteo.

Marx, C., y Engels, F. (1968). Obras escogidas. México: Grijalbo.

Marx, C., y Engels, F. (1974). Ideología alemana: Crítica de la novísima filosofía alemana en las personas de sus representantes Feuerbach, B. Bauer y Stirner y del socialismo alemán en las de sus diferentes profetas. (Quinta). Barcelona: Grijalbo.

Monrroy, M. (2012). Desempeño docente y rendimiento académico en Matemática de los alumnos de una Institución Educativa de Ventanilla - Callao (Tesis de Maestría). San Ignacio de Loyola, Lima.

OCDE. (2016). PISA Resultados Clave. Recuperado 9 de julio de 2017, a partir de https://www.oecd. org/pisa/pisa-2015-results-in-focus-ESP.pdf

Rosental, I. (2005). Diccionario filosófico. Lima: Huascarán.

Selsam, H. (1968). ¿Qué es filosofía? México: Grijalbo.

Shishkin, A. (1966). Ética marxista. México: Grijalbo.

SICRECE. (2016) ¿Cuánto aprenden nuestros estudiantes en las competencias evaluadas?

Stalin, J. (1972). ¿Anarquismo o socialismo? México: Grijalbo.

Suchodolski, B. (1965). Teoría marxista de la educación. México: Grijalbo.

Sujov, A. D. (1968). Las raíces de la religión. México: Grijalbo.

Yarlequé, L., Javier, L., Monroe, J., \& Nuñez, E. (2007). Investigación en educación y Ciencias Sociales. Huancayo. 